\title{
A review of typhoid fever in South African black children
}

\author{
M.E. Ellis ${ }^{1}$, A. Moosa ${ }^{2}$ and V. Hillier ${ }^{3}$ \\ ${ }^{1}$ Section of Infectious Diseases, Department of Medicine, King Faisal Specialist Hospital \& Research \\ Centre, PO Box 3354, Riyadh 11211, Kingdom of Saudi Arabia, ${ }^{2}$ Department of Paediatrics, University \\ of Natal Medical School, Durban, South Africa and ${ }^{3}$ University of Manchester Medical School, \\ Manchester, UK.
}

\begin{abstract}
Summary: Typhoid fever continues to escape swift diagnosis, even in an endemic country, and its multi-system nature led to delayed diagnosis in $25 \%$ of the patients in this study. This may have been an avoidable factor, leading to death in some patients through delay in instituting appropriate antimicrobial therapy. Neurological features and diarrhoea were particularly common in this paediatric population. Relative bradycardia has been shown to be a highly statistically significant finding for our group as a whole. Amoxycillin remains an effective and useful alternative to chloramphenicol. The mortality rate of $2.5 \%$ remains unchanged over the last $\mathbf{1 0}$ years. The relative inaccessibility to good primary health care, acceptable water supplies and santitation that the black South African child encounters cannot be ruled out as a co-factor.
\end{abstract}

\section{Introduction}

A third of the world's cases of typhoid fever occur in Africa, with an annual notification rate in South Africa of 4,000 - and accounts for $1.5 \%$ of paediatric admissions at King Edward VIII Hospital, Durban. Our paper reviews admissions over a recent 6-year period.

\section{Patients and methods}

A retrospective analysis of case records of black South African children admitted with typhoid to the King Edward VIII Hospital, Durban, between 1977 and 1983 was made. Diagnosis was based on positive blood cultures or negative cultures accompanied by a compatible clinical presentation, together with either a Widal titre of at least $1 / 640$ or a 4-fold change in titre. Details of the admitting history, physical examination, laboratory and radiological investigations, hospital course, antimicrobial therapy and follow-up were retrieved and appropriate data recorded on a uniform pro forma, subsequently transcribed on to a computer data format for analysis. The data were analysed using SPSS (Statistical Package for the Social Scientist) on the University of Manchester's

Correspondence: M.E. Ellis, F.R.C.P., D.C.H. Accepted: 12 July 1990
Regional Computer Centre's Amdhal/CDC 7600 computers using non-parametric tests where appropriate.

\section{Results}

Five hundred and eighty five children ( 314 males, 263 females, 8 not recorded) were admitted over the period studied, corresponding to between 70 and 90 cases annually, mainly in the hot rainy months of November through February, with a peak of 140 cases in 1980 and a nadir of 30 in 1981. The age range was between 6 weeks and 13 years - 352 children $(65 \%)$ were aged $6-11$ years; $48(9 \%)$ were aged 2 years or under. Four hundred and fifty six children $(78 \%)$ had positive blood cultures $(78 \%$ blood only, $9 \%$ blood + faeces, $1 \%$ blood + urine, $13 \% 3$ sites positive); 129 (22\%) did not have a positive culture but were included as typhoid on the basis of serology and a compatible clinical picture. Most children (information available on 347 patients) came from 4 large Natal townships which were relatively deprived of adequate water and sanitation. Patients travelled between 15 and 80 kilometres to reach the hospital. The mean weight (available for 433 patients) of the children at most ages was between the third and the fiftieth centile apart from those who were at the extremes of childhood (1 year or less, 12 years or more) who were equal to or less than the third centile. 


\section{Clinical presentation}

Fever was the most consistent feature $-396 / 450$ $(88 \%)$ children had a mean temperature of $38.6 \pm$ $1.2^{\circ} \mathrm{C}$ on admission. Following the admission, the vast majority, i.e. $280 / 334(84 \%)$ developed high fever $\left(\geqslant 39^{\circ} \mathrm{C}\right.$ ) (mean $\left.39.7 \pm 0.1\right)$ and $189 / 334$ $(57 \%)$ had fever in excess of $40^{\circ} \mathrm{C}$. Two patients exhibited hypothermia $\left(\leqslant 35^{\circ} \mathrm{C}\right)$. A total of 320 patients had adequate fever recordings; 231 of the 320 had symptoms prior to admission of $0-7$ days duration - of these 64 had a remittent pattern; 54 of the 320 had symptoms 8-14 days duration - of whom 3 had a constant pattern; 35 of the 320 had symptoms of $\geqslant 15$ days duration - of whom 11 had an intermittent pattern. Thus, overall, only $78 / 320$ had a temperature pattern appropriate to the duration of their symptoms. Thus, when the temperature patterns were compared to the duration of symptoms by Kruskal Wallis analysis of variance by Ranks, there was no significant difference in symptom duration for the different temperature patterns.

Figure 1 shows the pulse rate per minute by temperature. The line labelled 'actual' is a regression line (line of best fit) to the data and, superimposed upon this graph, is the line labelled 'expected' which is the expected pulse rate calculated by the formula expected rate $=$ (temperature in degrees $\mathrm{C}-37) \times 18$. This formula assumes that the pulse should rise by 18 beats per minute for every $1^{\circ}$ temperature rise ${ }^{l}$ and that the resting pulse of most of the children studied was approximately 100 beats per minute. Thus an expected pulse rate

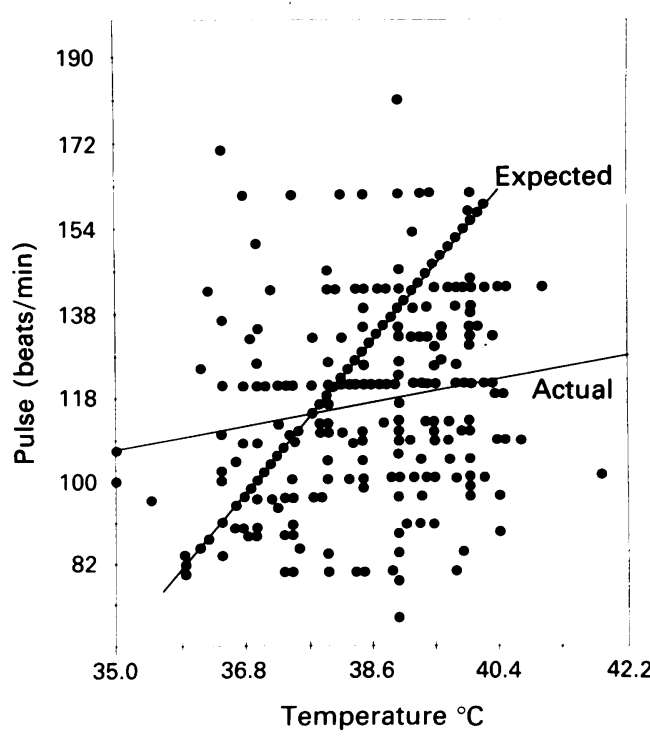

Figure 1 Expected and actual pulse rate. can be calculated for each child. A Wilcoxon signed Rank test on the pairs of values (observed and expected) was highly significant $(P<0.0001)$ with the majority of observed values lower than the expected ( 255 out of 356 cases available), suggesting that relative bradycardia is a feature of the disease.

At least one significant neurological abnormality was recorded in $450(77 \%)$ of patients including headache (unusual in children), and a withdrawn apathetic state in $293(50 \%)$. Global cerebral dysfunction (confusion, stupor, hyperreflexia, convulsions and encephalitis) occurred in $64(11 \%)$. A meningoencephalitic-like presentation led to diagnostic lumbar puncture in $152(26 \%)$, but the findings were usually physiological, though one patient had typhoid meningitis and several others had aseptic meningitis.

Features of gastrointestinal disease were the next most frequent mode of presentation. Abdominal pain occurred in $234(40 \%)$. Diarrhoea was common, particularly in young children under 2 years of age in whom it occurred in $374(64 \%)$ of cases. Constipation was rare. Blood or mucus per rectum was present in $29(5 \%)$, a distended abdomen in 123 $(21 \%)$, splenomegaly and hepatomegaly in 192 $(33 \%)$, respectively. Right upper quadrant/epigastric tenderness was found in $187(32 \%)$. Rose spots were recorded in only one patient who was desperately ill and developed intestinal perforation.

Bronchopulmonary involvement (cough, tachypnoea, wheeze) was found in $216(37 \%) ; 123(21 \%)$ had one or more abnormal chest auscultatory finding, (crepitations, rhonchi, bronchial breathing), 141/247 (57\%) had an abnormal chest radiograph (bronchial wall thickening and/or patchy perihilar shadowing and/or segmental consolidation).

Nephritis (haematuria, proteinuria, hypertension, oedema, reduced $\mathrm{C} 3$ levels) unassociated with urinary tract infection or schistosomiasis was found in the $29(5 \%)$, in whom symptoms were present.

Duration of symptoms of 493 patients ranged from 2-25 days prior to admission and the mean duration of each patient's longest symptom was $8.6 \pm 10.7$ days for 493 patients' data. Those with neurological manifestations and gastrointestinal presentation came to hospital sooner, but patients with generalized symptoms or nephritis came relatively late in the disease.

In over a quarter of cases, typhoid was not considered as either a primary or differential diagnosis but was dependent on subsequent blood cultures and serology. 


\section{Laboratory results}

The mean total white count was normal in $429 / 543$ (79\%) children when compared to control haematological values (data collected by the University of Natal Department of Paediatrics and Child Health). The mean white cell count was raised in the age group 0 - less than 2 years $\left(15 \times 10^{9} / 1\right.$ compared with the expected of $\left.10 \times 10^{9} / 1\right)$ and $\geqslant 5$ years $\left(7.6 \times 10^{9} / 1\right.$ compared to $\left.6.5 \times 10^{9} / 1\right)$. A slight neutrophilia was present in the age group $>3 \leqslant 4$ years $\left(5.4 \times 10^{9} / 1\right.$ compared with the expected of $\left.4.7 \times 10^{9} / 1\right),>2 \leqslant 3$ years $\left(6.5 \times 10^{9} / 1\right.$ compared to $\left.4.7 \times 10^{9} / 1\right)$ and $0<2$ years $\left(9.5 \times 10^{9} / 1\right.$ compared to $3.8 \times 10^{9} / 1$ expected).

A number of other laboratory abnormalities were present (Table I).

Five hundred and eighty two of the 585 patients had at least one stool and one urine sample screened for pathogenic bacteria, ova cysts and parasites. Concomitant bowel helminths were common, of which Ascaris lumbricoides occurred in 111 $(19 \%)$, Schistosoma mansoni ova were found in 17 (3\%) patients' stools and Schistosoma haematobium was detected in spun urine deposits of 230 $(40 \%)$ patients. Potentially pathogenic enteric bacteria isolated from the stools included shigella in $9(1.5 \%)$ patients and non-typhoidal salmonella in $67(11 \%)$ patients. No information is available for the usual prevalence of parasites and pathogenic bacteria in the healthy, normal paediatric black South African population.

\section{Widal serology}

Four hundred and eighty eight patients had ' $O$ ' Widal serology and 372 had ' $H$ ' Widal serology performed; 330 of these 488 had positive blood cultures of whom $205(62 \%)$ had an ' $O$ ' Widal titre of $\leqslant 320$ and in $106(32 \%)$ it was $\leqslant 40$. The numbers of patients with the corresponding ' $\mathrm{H}$ ' Widal titres for blood positive culture cases were $120 / 258(47 \%)$ and $45 / 258(17 \%)$ respectively (Figure 2). The Widal was not influenced by nutritional status, by the presence of positive cultures in 2 or more sites, or by time to defervescence. The presence of additional enteric pathogens such as shigella, or other salmonellae and Gram-negative bacteraemia was associated with a higher proportion of patients having higher Widal titres (Figure 2).

Sixty-one patients had paired ' $H$ ' serological results (i.e. 2 values separated by $10-14$ days) and 49 of these $(78 \%)$ showed a 4 -fold titre change. Thirty-nine had positive blood cultures, of whom $31(80 \%)$ had a 4-fold titre change. Twenty-two patients did not have positive blood cultures of whom $17(77 \%)$ had a 4-fold change. Eighty-six patients had paired ' $O$ ' serological results and 74 $(86 \%)$ of these had a 4-fold titre change. Forty-nine had positive blood cultures, $42(86 \%)$ of whom displayed a 4-fold change. Of the remaining 37 who had negative blood cultures $32(87 \%)$ had a 4 -fold change.

\section{Treatment and outcome}

Amoxycillin was the most frequently used antibiotic and antibiotic therapy is shown in Table II. The mean time to defervescence was 6.9 days, 6 children sustained intestinal perforation, 4 significant gastrointestinal tract haemorrhage, 12 relapsed and 48 had change of antimicrobial therapy. Amoxycillin was associated with a shorter time to defervescence, fewer complications and lower mortality when compared to chloramphenicol, but the differences were not statistically significant apart from the larger number of patients who changed from chloramphenicol to amoxycillin compared to those who changed from amoxycillin

Table I Typhoid fever; other laboratory results

\begin{tabular}{lccc}
\hline & $\begin{array}{c}\text { Number } \\
\text { abnormal }\end{array}$ & $\begin{array}{c}\text { Number } \\
\text { studied }\end{array}$ & $\begin{array}{c}\% \text { of } \\
\text { patients }\end{array}$ \\
\hline Haemoglobin $<10 \mathrm{~g} / \mathrm{dl}$ & 157 & 441 & 36 \\
Platelets $<150 \times 10^{9} / 1$ & 60 & 147 & 30 \\
ESR $>100 \mathrm{~mm} / \mathrm{h}$ & 11 & 51 & 22 \\
Serum sodium $\leqslant 130 \mathrm{mmol} / 1$ & 173 & 428 & 40 \\
Serum potassium $\leqslant 3 \mathrm{mmol} / \mathrm{l}$ & 94 & 428 & 22 \\
Serum bicarbonate $\leqslant 20 \mathrm{mmol} / 1$ & 197 & 428 & 46 \\
Serum protein $\leqslant 60 \mathrm{~g} / \mathrm{l}$ & 65 & 261 & 25 \\
Serum alanine aminotransferase & 65 & 145 & 45 \\
$\geqslant 1.5 \times$ upper limit of normal & & & \\
together with a normal bilirubin & & & \\
\hline
\end{tabular}




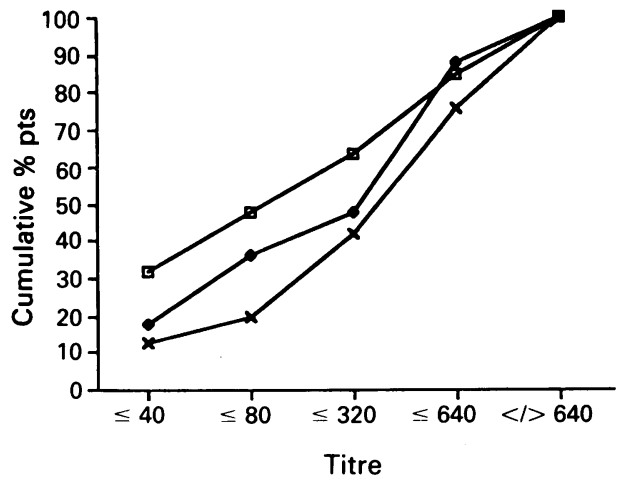

Figure 2 Cumulative percentage of patients with Widal titres: $\square-\square$, , $O$ '; $>$ ' 'H'; $\times-\times$, Shigella, Salmonella septicaemia.

to chloramphenicol (Table II). The reason for this change of treatment was unclear. Twelve children died (11 male, one female) - a mortality of $2.5 \%$ and 4 of these occurred in children under 1 year, representing a mortality of $15 \%$ for that age group. There was delay in arriving at a correct diagnosis in 11 of these 12 patients and delay in initiating correct therapy in 8. Causes of death included renal failure due to glomerulonephritis in 3, intestinal perforation 2, ileus 1, other Gram-negative sepsis 1, disseminated herpes simplex 1 and hepatic failure 1.

\section{Discussion}

Typhoid continues to be a significant cause of illness among black South African children. It is rare in white South African children - a direct effect of apartheid controlled social deprivation. The diagnosis was often missed or delayed, a reflection of the multi-system nature of the disease. The possibility of typhoid in any ill, febrile child, therefore, should always be borne in mind.

Certain classical clinical features are confirmed, including high fever, but there appears to be little support for the general belief that a particular temperature pattern relates to the duration of symptoms. Relative bradycardia, however, is confirmed and may be a useful clinical pointer. Constipation is said to be a feature of typhoid, but this was uncommon in this study where a gastroenteritis-like presentation was common particularly in very young infants. This feature has previously been thought uncommon by some authors ${ }^{2}$ and highlights the importance of excluding typhoid in the differential diagnosis of viral, bacterial and non-specific gastroenteritis. The mechanism of the diarrhoea is unknown but may reflect poor cell and humoral immune maturity, malnutrition related poor enterocyte development or a higher infected inoculum produced by faecal-oral contamination.

A single Widal titre did not appear to be a useful diagnostic tool since in approximately a third of our patients with positive blood cultures, it was low

Table II Antibiotic use and outcome

\begin{tabular}{lcccccc}
\hline & ALL & $\begin{array}{c}\text { Chloram- } \\
\text { phenicol }\end{array}$ & $\begin{array}{c}\text { Amoxy- } \\
\text { cillin }\end{array}$ & $\begin{array}{c}\text { Ampi- } \\
\text { cillin }\end{array}$ & $\begin{array}{c}\text { Co-trim- } \\
\text { oxazole }\end{array}$ & Other \\
\hline $\begin{array}{l}\text { No. of patients } \\
\begin{array}{l}\text { Time to defervescence } \\
\text { (days) (mean + s.d.) }\end{array}\end{array}$ & $6.9 \pm 4.7$ & $\begin{array}{c}7.6 \pm 4.7 \\
\text { Perforation }\end{array}$ & $6.8 \pm 4.6$ & $8.0 \pm 4.3$ & $9.0 \pm 8.2$ & $5.3 \pm 3.5$ \\
$\begin{array}{l}n(\%) \\
\begin{array}{l}\text { Haemorrhage } \\
n(\%)\end{array}\end{array}$ & $4(0.7)$ & $0(0)$ & $3(0.7)$ & $0(0)$ & $0(0)$ & $1(5)$ \\
$\begin{array}{l}\text { Relapse } \\
n(\%)\end{array}$ & $12(2.2)$ & $3(3.6)$ & $10(2.3)$ & $0(0)$ & $0(0)$ & $0(0)$ \\
$\begin{array}{l}\text { Carriage } \\
n(\%)\end{array}$ & $2(0.3)$ & $1(1.2)$ & $1(0.2)$ & $0(0)$ & $0(0)$ & $0(0)$ \\
$\begin{array}{l}\text { Change treatment } \\
n(\%)\end{array}$ & $48(8.7)$ & $15(8.0)$ & $17(4.0)$ & - & - & - \\
$\begin{array}{l}\text { Death } \\
n(\%)\end{array}$ & $12(2.1)$ & $2(2.4)$ & $3(0.7)$ & $0(0)$ & $1(17)$ & $6(30)$ \\
\hline
\end{tabular}

Note: The different numbers of patients on amoxycillin and chloramphenicol showing the variables 2-8 are not statistically significant, apart from the greater number on chloramphenicol who switched treatment to amoxycillin compared to those on amoxycillin who changed to chloramphenicol $(P<0.00001)$.

(Mann-Whitney $U$ test is used for testing difference in variable 2; Chi-squared test with continuity correction was used for variable 7; Fischer's Exact test ( 2 tailed) was used for testing the differences between the remaining variables) 
$(\leqslant 40)$, whilst in only $1 / 3$ of patients were the values commonly considered diagnostic (i.e. in excess of 320). Concomitant infection with other enteric pathogens tended to produce higher Widal titres which gives credence to the suggestion that nontyphoid gastrointestinal pathogens can affect the Widal. ${ }^{4}$ Our limited data on paired sera indicates that a 4-fold change in ' $\mathrm{O}$ ' or ' $\mathrm{H}$ ' titre occurs in most cases (and unrelated to documented bacteraemia) and that this might be more useful than a single isolated value.

Amoxycillin appears to be at least as effective as, and possibly associated with fewer complications than, chloramphenicol in the treatment of typhoid. Since the comparison, however, was not doubleblind, there is the possibility that patient selection occurred and so the conclusions are tentative. However, carefully controlled studies have been performed, such as the one by Scragg et al..$^{5}$ in which oral amoxycillin was shown to be superior to chloramphenicol when assessed by clinical response, relapse rate and carrier state.

\section{References}

1. Manson-Bahr, T.E.C. \& Apted, F.I.C. Salmonellosis. In: Manson's Tropical Diseases, 18th edition. Bailliere Tindall, Edinburgh, London, 1982, p. 384.

2. Colon, A.R. Gastrointestinal phenomena in childhood typhoid fever. South Med J 1976, 69: 914.

3. Hornick, R.B. Typhoid fever. In: Hoeprich, L. (ed.) Infectious Disease, 3rd edition. Harper and Rowe, Philadelphia, 1983, pp. 662-673.
A mortality rate of $2.5 \%$ has not altered appreciably since the last review from this centre, ${ }^{6}$ but avoidable factors such as diagnostic delay and treatment delay were present in almost every child that died. Some patients had to travel unacceptably long distances to hospital and the late presentation in some symptom complex groups may be two further complicating factors which could be corrected by improving community health care facilities and health education, respectively.

\section{Acknowledgements}

We acknowledge the kind permission of the Consultant Paediatricians at the King Edward VIII Hospital, Durban, Natal to peruse the case notes of their patients, and we are particularly grateful to $\operatorname{Dr}$ A. Rubidge for her help and comments in this study. We are grateful to Miss B. Sherwin for the expert secretarial help. Dr M.E. Ellis was in receipt of a Medicine-Gilliland Travelling Fellowship.

4. Reynolds, D.W., Carpenter, R.L. \& Simon, W.H. Diagnostice specificity of Widals reaction for typhoid fever. JAMA 1970 214: 2192-2196.

5. Scragg, J.N. Further experience with amoxycillin in typhoid fever in children. Br Med J 1976, 2: 1031.

6. Scragg, J.N. Typhoid fever and its management with special reference to the disease in childhood. $S$ Afr J Hosp Med 1976, $556-561$. 